\title{
Ferramentas computacionais para a educação a distância e a realidade educacional no período pandêmico do Covid-19 no Brasil
}

DOI: $10.37702 / 2175-957 X . C O B E N G E .2021 .3664$

Isac Vinicius Maciel - isacvini@unifei.edu.br

Universidade Federal de Itajubá

Rua Canário 185

35904-013 - Itabira - MG

Pedro de Souza Mattioli - pedraomattioli01@unifei.edu.br

Universidade Federal de Itajubá

Rua Vinte E Um de Abril 270

12600-290 - Lorena - SP

Priscilla Chantal Duarte Silva - priscillachantal@unifei.edu.br

Universidade Federal de Itajubá

Rua Irmã Ivone Drumond 200

35903-087 - Itabira - MG

Wagner Cipriano da Silva - wagnerbhbr@gmail.com

Faculdade Única

Rua Dr. Ronaldo de Souza 24

35179-000 - Santana do Paraiso - MG

Resumo: $O$ ensino a distância é uma modalidade de ensino que, durante muito tempo, tem sido uma alternativa para os estudantes, principalmente, para àqueles que não têm condições de frequentar a graduação no formato presencial por diversos fatores como: condições financeiras insuficientes; morar em regiões afastadas da cidade; ter filhos; motivos de trabalho, entre outros. Além disso, com a chegada do período pandêmico do COVID-19 no país, ela se tornou a principal alternativa não só para atender as urgências, mas também para o prosseguimento das atividades e conteúdo do ensino presencial, tornando necessária a adaptação e reformulação das práticas educativas neste contexto. Diante disso, para favorecer o aprendizado desses estudantes, as instituições de ensino utilizam várias ferramentas computacionais que auxiliam o acesso e permanência nos 
cursos ofertados, bem como um melhor aproveitamento dos conteúdos propostos. Este estudo tem como objetivo analisar algumas ferramentas computacionais utilizadas para o ensino a distância, citando as plataformas digitais e destacando suas vantagens e desvantagens, além de avaliar a efetividade e relevância de cada recurso empregado. Utiliza-se o método tipo survey, a partir da aplicação da técnica de um questionário estruturado, direcionado aos estudantes, com o intuito de avaliar a qualidade do ensino a distância do ponto de vista deles. Os resultados apontam que ensino a distância é muito procurado por alunos, principalmente no contexto da pandemia, porém esta modalidade possui diversas falhas, especialmente no que se refere as ferramentas computacionais e no mau uso dessas. Portanto, conclui-se que o EaD tem uma capacidade enorme de crescimento, porém ainda não correspondeu a todas as expectativas que se espera, dificultando o processo de evolução desta modalidade

Palavras-chave: Ensino a distância; ferramentas computacionais; plataformas digitais; COVID-19. 


\section{FERRAMENTAS COMPUTACIONAIS PARA EDUCAĈ̃O A DISTÂNCIA E A REALIDADE EDUCACIONAL NO PERÍODO PANDÊMICO DO COVID-19 NO BRASIL}

\section{INTRODUÇÃO}

As diversas transformações que aconteceram no século passado possibilitaram a constante inovação da Tecnologia da Informação e Comunicação. Com o advento da Internet em 1969, criada inicialmente para fins militares durante a Guerra Fria, ocorreram diversos avanços tecnológicos, tais como: o surgimento do microcomputador e a grande difusão que se deu com a criação do computador pessoal, sendo hoje uma ferramenta de primeira necessidade no nosso cotidiano. Estes avanços trouxeram relevantes contribuições para a vida em sociedade, principalmente para a área educacional, uma vez que as pessoas tinham dificuldades em comparecer presencialmente nas escolas ou universidades devido a diversos fatores, tais como: distância da residência para a instituição de ensino, mobilidade urbana, dificuldade do estudante em conciliar trabalho e estudos, alto custo dos cursos presenciais e sobrecarga de trabalho.

No entanto, com a criação do EaD (ensino a distância), criado no intuito de solucionar estes problemas, tornou-se viável a realização de atividades e aulas presenciais com flexibilidade de horário, possibilitando o direito e acesso à uma educação para todos. Embora ainda cercada de preconceitos por muitos que a consideram uma espécie de sub educação comparada ao ensino presencial, a EaD tem rompido paradigmas e ganhado espaço no âmbito educacional. Em decorrência do estado de emergência do COVID-19, proveniente da declaração de pandemia do novo Coronavírus, em março de 2020, as medidas de contenção da propagação do vírus centraram-se no isolamento e distanciamento social além do uso de máscara e higienização das mãos e ambientes.

Desde o início da pandemia, as escolas de todos os níveis educacionais fecharam as portas por determinações governamentais na tentativa de evitar aglomerações. Nesse cenário, o ensino a distância tornou-se não só uma alternativa para atender as urgências, mas em muitas realidades educacionais, a única maneira de prosseguir com as atividades e conteúdos propostos pelo ensino presencial. Cada nível educacional, portanto, teve de se adaptar e reinventar práticas educativas capazes de continuar o desenvolvimento do ensino apesar de todo o infortúnio gerado pelo período pandêmico.

Jaimes (2020) destaca que a educação a distância tem sido uma ferramenta indispensável para promover a aprendizagem. E isso só foi possível pelo emprego das tecnologias de informação e comunicação (TICs). Segundo Rosenberg (2006), a nova geração de estratégias de estudo é representada pela web 2.0, ambiente em que os estudantes se tornam agentes ativos do processo de ensino/aprendizagem e os professores se tornam facilitadores.

A fim de analisar se as plataformas digitais de Educação a Distância estão atendendo às necessidades do ensino e aprendizagem na atualidade, o presente estudo propõe a análise de algumas plataformas, com o intuito de comparar a efetividade e levantar as respectivas características, para propor modificações e consequentemente melhorias. Dessa forma, todos se tornam não só bons contribuidores, como também consumidores do conhecimento. 


\section{ENSINO A DISTÂNCIA}

A Educação a Distância $(E a D)$ é uma modalidade de ensino em que não é necessário que professores e alunos vivenciem o processo de ensino e aprendizagem de forma presencial, isto é, não é necessário um espaço físico comum para que a aprendizagem aconteça. Os horários normalmente atendem às necessidades do estudante para que seja possível a educação com maior flexibilização de horário e local. A interação entre eles ocorre através de recursos tecnológicos digitais, ou seja, há a utilização de Tecnologias da Informação e da Comunicação (TIC) para promover esta interação.

A utilização de TIC como instrumento facilitador da aquisição e compartilhamento de conhecimentos condiz com o principal objetivo da educação, presente no significado da palavra no dicionário Aurélio, que afirma que a educação é relativa "ao processo de desenvolvimento da capacidade física, intelectual e moral da criança e do ser humano em geral, visando à sua melhor integração individual e social" (FERREIRA, 1986, p. 499).

Mattar et al. (2020) orientam que, na educação a distância (EaD) no Brasil, o papel do tutor configura uma tarefa importante nessa modalidade. Eles atuam como tutores presenciais como aqueles que trabalham nos polos de apoio e como tutores a distância nos ambientes virtuais de aprendizagem (AVA). Esse é um dos motivos pelos quais o EaD não é o mesmo que ensino remoto emergencial ou trabalho remoto, pois no remoto não há a presença do tutor para auxiliar o professor. Além disso, os autores afirmam que o tutor desempenha um papel pedagógico, intelectual e social, uma vez que realiza atividades, avalia respostas, relaciona comentários, mantém contato com a turma, oferece feedback e mantém tom amigável com os alunos, entre outras tarefas.

Nesse sentido, de acordo com Beltrán (1981) apud Trigueiro (2001), a utilização desses dois modelos atinge o objetivo principal da comunicação: ser um meio de interação social através de um intercâmbio de conhecimentos, ou seja, um compartilhamento de experiências por meio do diálogo e da participação entre os seres humanos, realizado de forma livre e igualitária, enfatizando o conhecimento como fruto das interações sociais, conforme teoria do socioconstrutivismo de Vygotsky, descrita por Boiko \& Zamberlan (2001), como a aprendizagem um fruto da interação.

${ }^{1} \mathrm{O}$ surgimento do $\mathrm{EaD}^{2}$ se deu em meio a uma evolução tecnológica global, que influenciou na mudança de paradigma educacional. Diante disso, surgiram modalidades de ensino com a utilização de TDIC - Tecnologias Digitais da Informação e Comunicação, ressignificando a relação professor-aluno.

\section{PLATAFORMAS DIGITAIS}

Os Ambientes Virtuais de Aprendizagem (AVA) ou plataformas de EAD são responsáveis por fornecer as ferramentas necessárias para comunicação entre todos os envolvidos no processo de educação a distância. Segundo Atanásio, Pereira e Pereira (2006), os ambientes virtuais de aprendizagem (AVA), podem ser considerados como

\footnotetext{
${ }^{1}$ O sócio-construtivismo é uma teoria que vem se desenvolvendo, com base nos estudos de Vygotsky e seus seguidores, sobre o efeito da interação social, da linguagem e da cultura na origem e na evolução do psiquismo humano. Segundo este referencial, o conhecimento não é uma representação da realidade, mas um mapeamento das ações e operações conceituais que provaram ser viáveis na experiência do indivíduo. Portanto, a aprendizagem é um resultado adaptativo que tem natureza social, histórica e cultural. (Boiko \& Zamberlan, 2001, p.51)

${ }^{2}$ No início, o EaD era voltado para cursos por correspondência, isto é, cursos que serviam de complemento para a formação profissional e universitária, utilizando materiais impressos como base de estudo. Com o tempo, a modalidade passou a ser oferecida não só para cursos de graduação, mas também para cursos técnicos, livres, preparatórios, entre outros, utilizando como recursos os slides, o rádio e por fim os dispositivos eletrônicos com acesso à Internet.
} 
uma nova mídia na evolução, proporcionando a todos os envolvidos uma forma para expor seus pensamentos, uma maneira de organização da informação e o modo de aprendizagem. Desse modo, essas plataformas virtuais devem proporcionar ao usuário: interatividade, usabilidade, integridade e desempenho, tendo em vista que a interação vai além do espaço interno virtual, sendo capaz de facilitar a inclusão social e a colaboração em grupo, com o intuito de atender as necessidades dos envolvidos. Neste capítulo, abordaremos sobre algumas das principais plataformas digitais utilizadas no Brasil e no mundo. Será apresentado um breve estudo comparativo entre elas, avaliando as principais características de cada uma. Sendo assim, segue a apresentação de algumas plataformas digitais: Moodle, TelEduc, Eureka, LearningSpace.

Figura 1 - Apresentação da plataforma do site Moodle

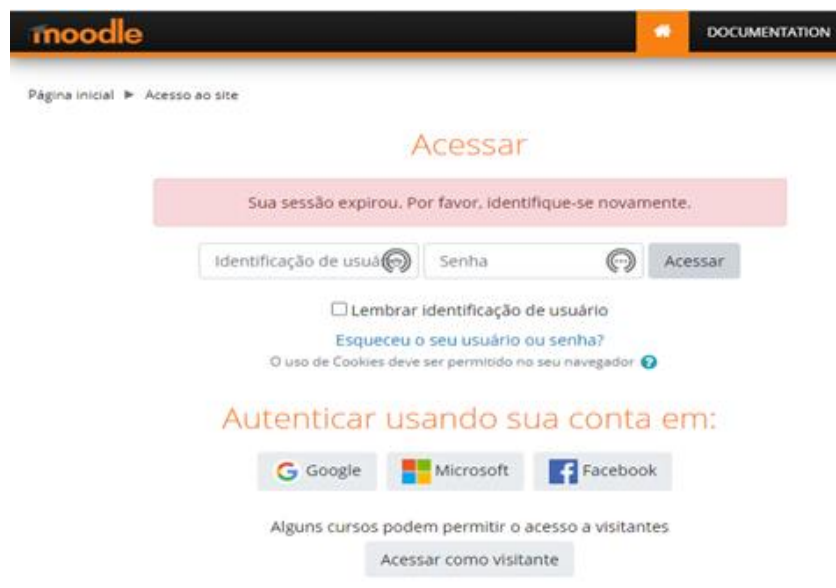

Fonte: https://moodle.org/login/index.php

A palavra Moodle é originalmente um acrônimo para Modular Object-Oriented Dynamic Learning Environment - Ambiente de Aprendizagem Dinâmico Modular Orientado a Objeto, útil principalmente para programadores e profissionais da educação. É também um verbo que descreve o processo de se passar por algo tranquilamente, fazendo as coisas quando surgir oportunidade, uma divertida atividade manual que pode nos levar a ter insights criativos. Como tal, aplica-se tanto ao modo como o Moodle foi desenvolvido, quanto ao modo como um estudante ou professor pode abordar o estudo ou o ensino em um curso online.

Figura 2 - Apresentação do site TelEduc

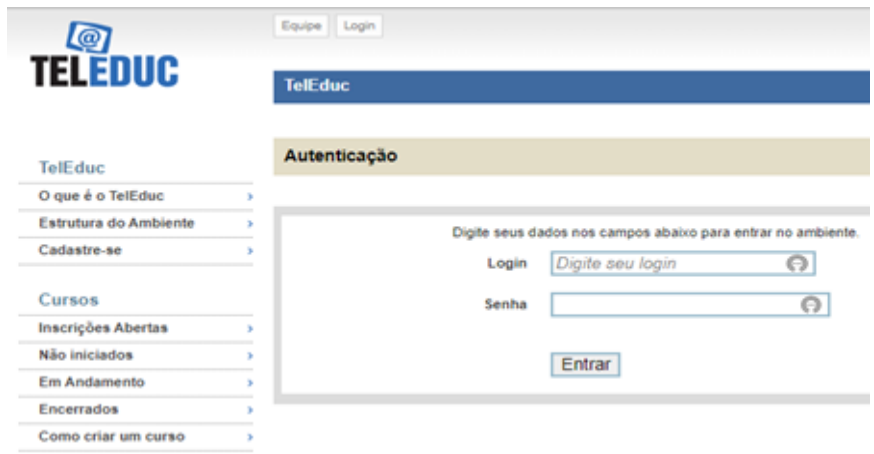

Fonte: http://teleduc4.multimeios.ufc.br/pagina_inicial/autenticacao_cadastro.php 
O TelEduc é um ambiente para realização de cursos a distância através da Internet. Está sendo desenvolvido no Nied (Núcleo de Informática Aplicada à Educação) sob a orientação da Profa. Dra. Heloísa Vieira da Rocha do Instituto de Computação da Unicamp (Universidade Estadual de Campinas), a partir de uma metodologia de formação de professores construída com base na análise das várias experiências presenciais realizadas pelos profissionais do núcleo. $O$ ambiente é parte integrante da dissertação de mestrado "Formação a Distância de Recursos Humanos para Informática Educativa" de autoria de Alessandra de Dutra e Cerceau.

Figura 3 - Apresentação do site Eureka

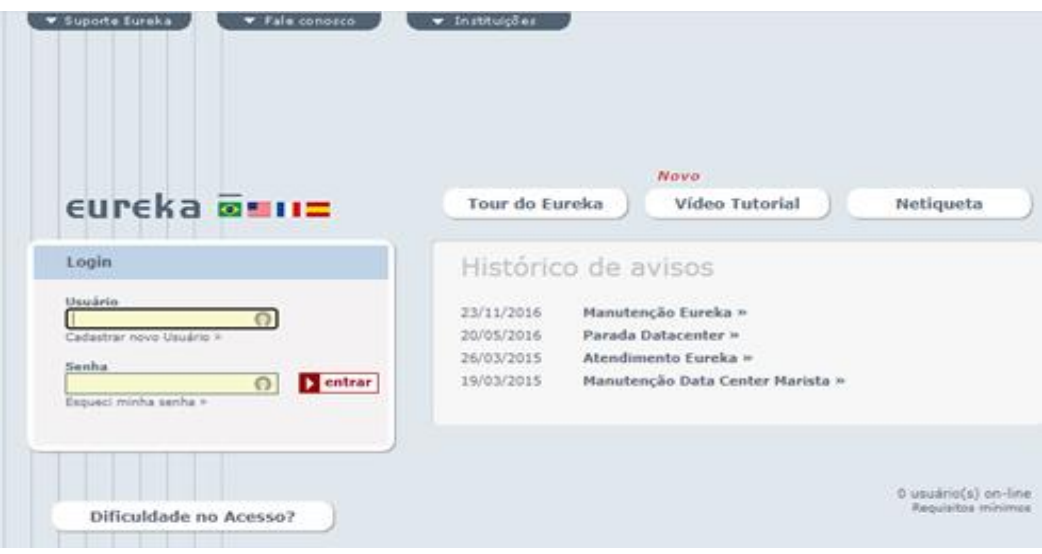

Fonte: https://eureka.pucpr.br/entrada/index.php?acao=carregando

O Eureka é o Ambiente Virtual de Aprendizagem da PUCPR. Esta ferramenta é apresentada à comunidade científica por meio do artigo presente no link $<$ https://www.redalyc.org/pdf/1891/189118140002.pdf>, onde são apresentados os resultados da institucionalização do ambiente na PUC-PR. Nesse ambiente, o estudante tem a oportunidade de interagir com os demais participantes de sua sala de forma criativa, dinâmica e desafiadora, tendo como essência o diálogo, a pesquisa e a descoberta.

Figura 4 - Apresentação do site LearningSpace

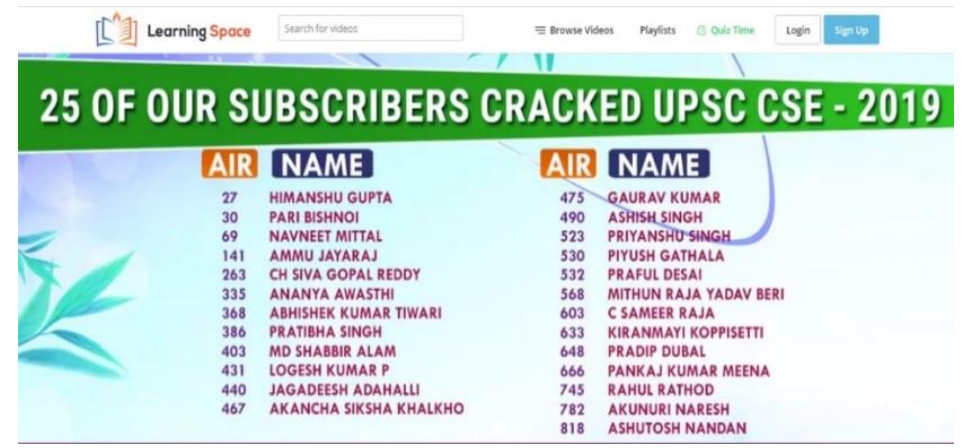

Fonte: https://www.learningspacedigital.com/

O desenvolvimento do site, que começou em maio de 2006, oferece uma ampla gama de áreas para Educação a Distância. Em abril de 2008, o OpenLearn atingiu a meta de ter 5.400 horas de conteúdo de aprendizagem no LearningSpace e 8.100 horas no LabSpace. O ambiente inclui ferramentas de auto-avaliação, fóruns e uma experiência 
personalizada de colaboração ao aluno, com criação e utilização de materiais de aprendizagem. Para comunicação, o LearningSpace utiliza ferramentas de rede social para replicar os diferentes modos informais de comunicação e aprendizagem que acontecem em um campus tradicional. Na tabela a seguir tem-se um comparativo de todas que foram citadas acima:

Tabela 1 - Estudo comparativos das plataformas

\begin{tabular}{|c|c|c|c|c|c|c|c|}
\hline Plataforma & $\begin{array}{l}\text { Sistema de } \\
\text { distribuição }\end{array}$ & $\begin{array}{c}\text { Princípios } \\
\text { pedagógico } \\
\text { s }\end{array}$ & $\begin{array}{c}\text { Aprendizage } \\
\text { m } \\
\text { colaborativa }\end{array}$ & Interatividade & Multimídia & Usabilidade & Acessível \\
\hline Eureka & $\begin{array}{l}\text { Desenvolvid } \\
\text { o para } \\
\text { comunidade } \\
\text { acadêmica } \\
\text { da PUCPR }\end{array}$ & Não informa & Não informa & $\begin{array}{l}\text { Correio } \\
\text { eletrônico }\end{array}$ & $\begin{array}{l}\text { Oferece } \\
\text { áudio com } \\
\text { o texto }\end{array}$ & $\begin{array}{l}\text { Facilidade de } \\
\text { uso Explicativa } \\
\text { quanto ao uso }\end{array}$ & $\begin{array}{l}\text { Não } \\
\text { acessível a } \\
\text { deficiente } \\
\text { auditivo } \\
\text { Parcialmente } \\
\text { acessível ao } \\
\text { deficiente } \\
\text { visual (só } \\
\text { áudio, sem } \\
\text { leitor de tela) }\end{array}$ \\
\hline Moodle & $\begin{array}{l}\text { Pode ser } \\
\text { redistribuído } \\
\text { ou } \\
\text { modificado } \\
\text { nos termos } \\
\text { da GNU } \\
\text { (General } \\
\text { Public } \\
\text { License) }\end{array}$ & $\begin{array}{l}\text { Proposta } \\
\text { colaborativa }\end{array}$ & $\begin{array}{l}\text { Fórum de } \\
\text { discussão } \\
\text { Gestão de } \\
\text { conteúdo } \\
\text { Blogs } \\
\text { Wikis }\end{array}$ & $\begin{array}{l}\text { Videoconferênci } \\
\text { a } \\
\text { Certificados } \\
\text { digitais }\end{array}$ & $\begin{array}{l}\text { Não } \\
\text { informa }\end{array}$ & $\begin{array}{l}\text { Permite } \\
\text { acesso ao } \\
\text { visitante } \\
\text { Oferece } \\
\text { ferramenta } \\
\text { p/deficiência } \\
\text { visual }\end{array}$ & $\begin{array}{l}\text { Parcialmente } \\
\text { acessível p/ } \\
\text { deficiente } \\
\text { visual (com } \\
\text { leitor de tela) }\end{array}$ \\
\hline $\begin{array}{l}\text { LearnigSpac } \\
\text { e }\end{array}$ & $\begin{array}{l}\text { Pode ser } \\
\text { redistribuído } \\
\text { ou } \\
\text { modificado } \\
\text { nos termos } \\
\text { da GNU } \\
\text { (General } \\
\text { Public } \\
\text { License) }\end{array}$ & $\begin{array}{l}\text { Proposta } \\
\text { colaborativa }\end{array}$ & $\begin{array}{l}\text { Fórum de } \\
\text { discussão } \\
\text { Chat } \\
\text { Avisos } \\
\text { Estimula uso } \\
\text { das redes } \\
\text { sociais }\end{array}$ & $\begin{array}{l}\text { Utiliza redes } \\
\text { sociais da web } \\
\text { como ferramenta } \\
\text { da interação }\end{array}$ & $\begin{array}{l}\text { Utiliza } \\
\text { redes } \\
\text { sociais da } \\
\text { web como } \\
\text { ferrament } \\
\text { a de } \\
\text { interação }\end{array}$ & $\begin{array}{l}\text { Explicativa } \\
\text { quanto ao uso } \\
\text { Possui fóruns } \\
\text { sobre } \\
\text { funcionalidade } \\
\text { s }\end{array}$ & $\begin{array}{l}\text { Afirma } \\
\text { cumprir } \\
\text { diretrizes de } \\
\text { acessibilidad } \\
\text { e do w3c }\end{array}$ \\
\hline
\end{tabular}

Fonte: https://periodicos.ufsc.br/index.php/eb/article/download/1518-2924.2010v15nesp2p65/15763

De acordo com a tabela 1, pode-se observar que existe uma grande desigualdade entre as plataformas, tendo em vista que algumas apresentam mais recursos do que as outras. Além disso, a maioria possui uma grande falha no que se refere à acessibilidade, principalmente das pessoas deficientes visuais. Todas apresentam recursos de interação que se centram mais na comunicação escrita e visual, sobretudo. A ferramenta comunicacional é muito importante na $\mathrm{EaD}$, na tentativa de suprir a possível carência da interação ${ }^{3}$ face a face.

\section{METODOLOGIA}

Para o levantamento de informações e conhecimentos acerca do tema, utilizaramse livros, artigos e obras como base para o desenvolvimento do projeto de estudo, portanto esta pesquisa é caracterizada como bibliográfica. A pesquisa bibliográfica

\footnotetext{
${ }^{3} \mathrm{Na}$ modalidade a distância tudo é registrado por escrito. Os fóruns e debates consistem em ferramentas de interação de participação entre os colegas da turma, o que favorece as relações interpessoais no ambiente virtual.
} 
segundo Fachin (2010) constitui-se na base para as demais, o que permite orientar os outros estudos. Como método de pesquisa, foi utilizada a plataforma Survey Monkeys, no qual as perguntas de múltiplas escolhas foram elaboradas, direcionando para a obtenção de respostas relacionadas à qualidade, dificuldade e adaptação dos alunos ao EaD. A escolha desse método de pesquisa foi devido à sua eficiência em verificar, através de amostras, a opinião da população. Portanto, este estudo é de natureza quantitativa. Segundo Gil (2010), o método quantitativo baseia-se na quantificação nas modalidades de coleta de informações e no seu tratamento.

Como coleta de dados, realizou-se a aplicação de um questionário utilizando o método do tipo survey, sendo aplicado com o objetivo de avaliar a qualidade e efetividade do Ensino a Distância, ou seja, avaliar o nível didático-pedagógica dessa modalidade de ensino, tais como os desafios enfrentados pelos alunos, no período pandêmico.

O questionário foi aplicado para 40 alunos de universidades brasileiras públicas e privadas, de ensino de engenharia. A faixa etária dos estudantes centra-se concentra em 18 a 30 anos. O questionário é composto por 10 questões de múltipla escolha e ficou disponível online, aproximadamente no prazo de uma semana, especificamente do dia $27 / 11 / 2020$ até $04 / 12 / 2020$. As questões foram produzidas, respeitando-se o anonimato e a individualidade. A seguir, apresentam-se as perguntas com as respostas deste questionário.

Tabela 2 - Questões Survey

\begin{tabular}{|c|c|c|}
\hline Aspecto & Questão & Pergunta \\
\hline $\begin{array}{l}\text { Percepção dos estudantes quanto ao } \\
\text { EaD }\end{array}$ & Q1 & Qual é a sua percepção sobre o ensino a distância? \\
\hline $\begin{array}{l}\text { Visão dos estudantes quanto ao uso das } \\
\text { plataformas no Ead }\end{array}$ & Q2 & $\begin{array}{l}\text { Qual é a sua opinião sobre as plataformas digitais do } \\
\text { EaD? }\end{array}$ \\
\hline $\begin{array}{l}\text { Exploração / Utilização das plataformas } \\
\text { pelos professores }\end{array}$ & Q3 & $\begin{array}{l}\text { As plataformas são bem exploradas /utilizadas pelos } \\
\text { professores? }\end{array}$ \\
\hline Maior dificuldade enfrentada no EaD & Q4 & $\begin{array}{l}\text { Qual é a maior dificuldade enfrentada por você no } \\
\text { EaD? }\end{array}$ \\
\hline $\begin{array}{l}\text { Visão dos estudantes sobre a atuação } \\
\text { do professor nas disciplinas em EaD }\end{array}$ & Q5 & $\begin{array}{l}\text { Como você avalia a atuação do professor nas } \\
\text { disciplinas no EaD ou ensino remoto? }\end{array}$ \\
\hline $\begin{array}{lrr}\text { Importância dos } & \text { recursos } \\
\text { computacionais no EaD } & \end{array}$ & Q6 & $\begin{array}{l}\mathrm{Na} \text { sua opinião, qual é a importância dos recursos } \\
\text { computacionais no Ead? }\end{array}$ \\
\hline $\begin{array}{l}\text { Preferência e capacidade } \\
\text { substituição de } \\
\text { relação à outra }\end{array}$ & Q7 & $\begin{array}{l}\text { Na sua opinião, uma modalidade pode substituir a } \\
\text { outra? }\end{array}$ \\
\hline $\begin{array}{l}\text { Faria novamente um curso EaD ou } \\
\text { indicaria a alguém }\end{array}$ & Q8 & $\begin{array}{l}\text { Você faria novamente um curso ou disciplina a } \\
\text { distância? }\end{array}$ \\
\hline $\begin{array}{l}\text { Acesso ao conteúdo das disciplinas na } \\
\text { modalidade a distância }\end{array}$ & Q9 & $\begin{array}{l}\text { Como você avalia o acesso ao conteúdo das disciplinas } \\
\text { na modalidade a distância? }\end{array}$ \\
\hline
\end{tabular}

Fonte: dados dos autores

Embora os termos "ensino remoto" e "ensino a distância" sejam considerados como sinônimos no contexto pandêmico, por muitos estudantes, sabe-se que não representam os mesmos contextos. Na literatura o "ensino remoto" surgiu a partir da necessidade de se desenvolver atividades assíncronas e síncronas como aulas ao vivo via web conferência em função do contexto pandêmico.

No ensino remoto, há uma condição temporária que pode envolver atividades síncronas ao vivo, bem como atividades assíncronas para a realização de tarefas. Dessa forma, considera-se a diferença básica neste estudo a presença ou não de plataformas específicas para o ensino não presencial. Sob esse aspecto, desconsiderou-se neste estudo a diferença semântica entre ensino remoto e ensino a distância, pois o objetivo era 
apenas avaliar a recepção da modalidade a distância, ou seja, qual era a percepção dos estudantes sobre estudar em casa, bem como o uso dos recursos computacionais na Educação, apesar de toda a adaptação da mediação didática e pedagógica que grande parte dos docentes fizeram nesse período. Ademais, partiu-se da hipótese de que os estudantes não considerariam a distinção semântica dos termos.

\section{RESULTADOS E DISCUSSÕES}

O acesso às perguntas foi disponibilizado aos estudantes por meio de grupos de redes sociais para divulgação. As perguntas foram: 1. Qual é a sua percepção sobre o ensino a distância? Nesta questão, objetivou-se avaliar a opinião dos estudantes quanto às vantagens do EaD sobre a modalidade presencial, no que concerne ao dinamismo, liberdade e autonomia, interação e inovação. Os resultados mostram que a maioria dos informantes acreditam que a modalidade $\mathrm{EaD}$ ou ensino remoto proporcionam mais liberdade e autonomia para realizar suas tarefas. Isso se deve ao fato de haver maior flexibilidade de horário de estudos, sobretudo quando há aulas assíncronas. Na realização das tarefas, os estudantes sentem também maior liberdade por realizarem dentro do espaço de tempo disponível.

Tabela 3 - Percepção dos estudantes quanto ao EaD

\begin{tabular}{|c|c|c|}
\hline $\begin{array}{l}\text { Opções de múltipla } \\
\text { escolha }\end{array}$ & Respostas & Quantidade de respondentes \\
\hline $\begin{array}{l}\text { É uma modalidade de ensino em } \\
\text { que o aluno tem mais liberdade } \\
\text { autonomia para realizar suas } \\
\text { tarefas }\end{array}$ & $56,41 \%$ & 22 \\
\hline $\begin{array}{l}\vec{E} \text { uma modalidade em que há } \\
\text { maior interação entre professor e } \\
\text { aluno }\end{array}$ & $0,00 \%$ & 0 \\
\hline $\begin{array}{l}\hat{E} \text { uma modalidade mais dinâmica } \\
\text { e inovadora }\end{array}$ & $10,26 \%$ & 4 \\
\hline Nenhuma das alternativas & $33,33 \%$ & 13 \\
\hline
\end{tabular}

Fonte: dados dos autores

Por não precisarem deixar a residência para ir à universidade, os estudantes vivenciaram uma realidade similar àqueles que antes da pandemia já realizavam cursos ou atividades na modalidade EaD: a de não precisar se deslocar para estudar. Nesse aspecto, observou-se que esses estudantes conseguiram ver como positivo essa nova dinâmica de se estudar. Na questão, perguntou-se quanto à avaliação dos estudantes sobre as plataformas digitais utilizadas: 2) Qual é a sua opinião sobre as plataformas digitais do EaD?

Tabela 4 - Visão dos estudantes quanto ao uso das plataformas no EaD

\begin{tabular}{lll}
\hline Opções de múltipla escolha & Respostas & Quantidade de respondentes \\
\hline As plataformas digitais do EaD são & $56,41 \%$ & 22 \\
boas, pois elas atendem às & & \\
minhas expectativas & &
\end{tabular}


Os resultados apontam que houve pequena diferença entre aqueles que consideram as plataformas como boas por atenderem às expectativas, comparativamente àqueles que não as consideram como satisfatórias. Muitas vezes, as expectativas relacionam-se às motivações internas e às impressões sobre o sistema.

Normalmente, aqueles que nunca tiveram uma experiência com o EaD tendem a ter a expectativa de que apenas o suporte é diferente e acreditam que apenas ocorrerá uma "adaptação" ou transferência do que é ensinado na modalidade presencial no EaD. O mesmo ocorre com os docentes. Alguns docentes tentam reportar as aulas do presencial para o EaD. Contudo, observa-se que as plataformas criadas para o EaD formulam recursos de interação para propiciar uma participação mais ativa dos estudantes, bem como exploram recursos computacionais para tentarem suprir a falta da interação face a face, haja vista que a interatividade encurta distâncias, e representa um fator preponderante para o sucesso do processo de construção do conhecimento no ensino remoto ou na EaD.

$\mathrm{Na}$ questão 3, pergunta-se: as plataformas são bem exploradas/ utilizadas pelos professores? Nessa questão, a expectativa era verificar se os estudantes observam o desempenho e habilidade do professor em lidar com os recursos computacionais das plataformas na orientação e desenvolvimento das suas aulas na modalidade a distância. Os resultados indicam que a maior parte dos informantes alega que nem sempre esses recursos são explorados ou utilizados pelos docentes, o que pode levar a crer que tendem a seguir a mesma linha do presencial.

Tabela 5 - Exploração / Utilização das plataformas pelos professores

\begin{tabular}{lll}
\hline Opções de múltipla escolha & Respostas & Quantidade de respondentes \\
\hline Sim & $25 \%$ & 10 \\
\hline Não & $15 \%$ & 6 \\
\hline Às Vezes & $60 \%$ & 24 \\
\hline
\end{tabular}

Fonte: dados dos autores

Na questão 4: "Qual é a maior dificuldade enfrentada por você no EaD"? O objetivo era identificar as possíveis barreiras encontradas pelos estudantes no EaD. No quadro a seguir, pode-se observar que a maior dificuldade reconhecida pelos estudantes foi a comunicação e a interação com colegas e professores. Embora os recursos tecnológicos e computacionais como os serviços de videoconferência, tais como: Google Meet, Cisco Webex e Zoom, ofereçam a oportunidade de se trabalhar a interação com recursos de câmera de vídeo, na opinião dos estudantes a interação tanto com os colegas, quanto com os professores não se dá na mesma forma.

Em geral, entre os estudantes, observa-se que o comprometimento da interação com os colegas se dá, principalmente, nas tarefas em grupo, pela falta do contato físico. Sob esse aspecto, vale lembrar que alguns docentes utilizam recursos como Google Docs e Google Teams, para que os alunos possam interagir nas atividades em equipe, porém na visão dos estudantes não é da mesma forma que na modalidade presencial. Dessa forma, os resultados revelam que essa carência da comunicação e interação da modalidade presencial seja também proveniente da cultura. Nesse sentido, faz-se necessária uma mudança de paradigmas por parte das instituições de ensino para que os estudantes e professores utilizem mais esses recursos como forma de desenvolver uma cibercultura também no âmbito educacional. Em segundo lugar, o ambiente de estudo foi apontado pelos estudantes como algo que compromete o ensino a distância. Isso se dá, em grande parte, ao fato de não terem um espaço físico reservado para os 
estudos. Como o período pandêmico foi inesperado, a maioria das famílias não se prepararam para terem aulas nas residências. Nesse sentido, a falta de um espaço adequado foi descrita pelos estudantes como um fator importante.

Ademais, com o home office, muitas empresas adotaram a alternativa de deixarem seus funcionários trabalharem de casa. Com efeito, os estudantes tiveram que conciliar os mesmos espaços e ainda, em alguns casos, o mesmo equipamento, para todos realizarem as atividades remotas. Sob esse aspecto, não se pode comparar o aluno de EaD que optou por essa modalidade por razões pessoais com os estudantes de ensino remoto, que foram obrigados a seguir a modalidade a distância por falta de opção, em decorrência do estado de calamidade pública que a pandemia do Covid-19 proporcionou ao mundo.

Tabela 6 - Maior dificuldade enfrentada no EaD

\begin{tabular}{lll}
\hline Opções de múltipla escolha & Respostas & Quantidade de respondentes \\
\hline Ambiente de estudo limitado & $27,50 \%$ & 11 \\
\hline Organização de tarefas & $17,50 \%$ & 7 \\
\hline $\begin{array}{l}\text { Comunicação e interação } \\
\text { colegas e professores }\end{array}$ & $50,00 \%$ & 20 \\
\hline Qualidade da internet & $5,00 \%$ & 2 \\
\hline
\end{tabular}

Fonte: dados dos autores

$\mathrm{Na}$ questão 5, perguntou-se aos estudantes sobre o papel do professor nas disciplinas em EaD. Os resultados indicam que grande parte dos informantes consideram razoável a atuação do professor na modalidade a distância. Os estudantes argumentam que, grosso modo, as expectativas não estão sendo cumpridas. Sob esse aspecto, de um lado, deve-se trazer à baila que muitos docentes que atuam no ensino remoto, no cenário pandêmico atual, nunca tiveram experiência com ferramentas ou plataformas de EaD. De outro, tem-se estudantes que esperam aulas mais interativas e que, de alguma forma, assemelham-se às presenciais. Nesse contexto, acredita-se que a razoabilidade apresentada pela opinião dos estudantes pode estar relacionada a essas questões.

Tabela 7 - Visão dos estudantes sobre a atuação do professor nas disciplinas em EaD

\begin{tabular}{lll}
\hline Opções de múltipla escolha & Respostas & Quantidade de respondentes \\
\hline $\begin{array}{l}\text { Bom, pois as minhas expectativas } \\
\text { estão sendo supridas }\end{array}$ & $22,50 \%$ & 9 \\
\hline $\begin{array}{l}\text { Razoável, pois algumas das } \\
\text { minhas expectativas estão sendo }\end{array}$ & $30,00 \%$ & \\
supridas, porém outras não. & & 1 \\
$\begin{array}{l}\text { Fraco, pois as minhas } 2,50 \% \\
\text { expectativas não estão sendo } \\
\text { supridas }\end{array}$ &
\end{tabular}

Fonte: dados dos autores

$\mathrm{Na}$ questão 6, verificou-se a opinião dos estudantes quanto à importância dos recursos computacionais no EaD. No quadro a seguir, pode-se observar que os estudantes consideram que os recursos computacionais auxiliam na obtenção de informações, facilitando a aprendizagem. 
Tabela 8 - Importância dos recursos computacionais no EaD

\begin{tabular}{|c|c|c|}
\hline Opções de múltipla escolha & Respostas & Quantidade de respondentes \\
\hline $\begin{array}{l}\text { Facilita a interação entre } \\
\text { professor e aluno }\end{array}$ & $10,26 \%$ & 4 \\
\hline $\begin{array}{l}\text { Maior obtenção de informações } \\
\text { das matérias abordadas pelas } \\
\text { disciplinas, mantendo os alunos } \\
\text { atualizados }\end{array}$ & $48,72 \%$ & 19 \\
\hline $\begin{array}{l}\text { Fácil acesso aos conteúdos das } \\
\text { disciplinas }\end{array}$ & $25,64 \%$ & 10 \\
\hline Todas as alternativas & $15,38 \%$ & 6 \\
\hline
\end{tabular}

Fonte: dados dos autores

$\mathrm{Na}$ questão 7, perguntou-se se o EaD supre a ausência do ensino presencial. Nessa questão, objetivou-se analisar a opinião dos estudantes sobre preferência e capacidade de substituição de uma modalidade sobre a outra. Os resultados mostram que alguns consideram que é possível, isto é, supre o que se tem na modalidade presencial. Porém, a maioria acredita que não supre. Por serem modalidades diferentes, cada uma tem as suas particularidades.

Tabela 9 - Preferência e capacidade de substituição de uma modalidade pela outra

\begin{tabular}{lll}
\hline Opções de múltipla escolha & Respostas & Quantidade de respondentes \\
\hline $\begin{array}{l}\text { Sim. É possível substituir } \\
\text { ensino presencial pelo EaD }\end{array}$ & $5,00 \%$ & 2 \\
\hline $\begin{array}{l}\text { Não. Não é possível substituir o } \\
\text { ensino presencial pelo EaD }\end{array}$ & $65,00 \%$ & 26 \\
Às vezes é possível substituir o & $30,00 \%$ & 12 \\
ensino presencial pelo EaD & & \\
\hline
\end{tabular}

Fonte: dados dos autores

$\mathrm{Na}$ questão 8, fica clara a posição dos estudantes quanto à satisfação e a opção de escolha desses quanto ao tipo de modalidade. $80 \%$ dos informantes afirmaram que não fariam novamente um curso $\mathrm{EaD}$ nem indicariam a outras pessoas. Isso revela que embora se tenha algumas vantagens com o ensino a distância e se compreenda a necessidade do isolamento social como o principal motivo para o emprego do ensino remoto no período pandêmico, a maioria dos informantes ainda preferem a modalidade presencial.

Tabela 10 - Faria novamente um curso EaD ou indicaria a alguém

\begin{tabular}{lll}
\hline Opções de múltipla escolha & Respostas & Quantidade de respondentes \\
\hline Sim & $20,00 \%$ & 8 \\
\hline Não & $80,00 \%$ & 32 \\
\hline
\end{tabular}

Fonte: dados dos autores

Na questão 9, objetivou-se investigar se os estudantes consideravam fácil ou difícil o acesso ao conteúdo das disciplinas. Essa questão revela que grande parte dos estudantes têm domínio das ferramentas tecnológicas e não veem dificuldades no uso delas, o que facilita os estudos na modalidade a distância. Acredita-se que isso se deve ao fato de os professores no ensino remoto buscarem usar ferramentas simples ou mesmo ao fato de os estudantes já terem certo domínio de informática. 
Tabela 11 - Acesso ao conteúdo das disciplinas na modalidade a distância

\begin{tabular}{lll}
\hline Opções de múltipla escolha & Respostas & Quantidade de respondentes \\
\hline Sim & $20,00 \%$ & 8 \\
\hline Não & $80,00 \%$ & 32 \\
\hline
\end{tabular}

Fonte: dados dos autores

Diante do exposto das respostas do questionário, observa-se que os alunos passam por dificuldades no EaD. Tendem a enxergar o EaD como uma solução para pessoas com realidades diferentes. Além disso, os alunos possuem opiniões divididas, ou seja, opiniões tanto positivas quanto negativas sobre o EaD, bem como a utilização dos recursos computacionais por parte deles mesmos e dos professores.

\section{CONSIDERAÇÕES FINAIS}

Após o estudo deste objeto de pesquisa, conclui-se que o Ensino a Distância e os recursos computacionais são grandes aliados para promover a construção de uma modalidade de ensino dinâmica e inovadora. Portanto, esta modalidade tem um grande potencial de evolução, tornando-se não só uma alternativa para suprir a ausência do Ensino Presencial, mas também uma solução para pessoas com realidades diferentes e um meio de facilitar o processo de democratização e ampliação do acesso à educação.

Como o público alvo da pesquisa foram alunos que estavam participando de uma realidade de ensino remoto emergencial, que não fora planejado para tal modalidade e que enfrentou uma série de desafios sem precedentes na história, é natural que a percepção dos estudantes com relação ao método de ensino seja deteriorada, mais ainda quando consideramos que, inevitavelmente, estes discentes estavam comparando a nova realidade com a modalidade presencial, que já não era mais possível se ter continuidade. Entretanto, um legado importante que no período de pandemia está sendo consolidado é a rápida adoção de ferramentas digitais em todo o contexto do processo de ensino e aprendizagem, não apenas para o ensino remoto, mas também metodologias que podem ser aplicadas em acréscimo aos já tradicionais métodos do modelo presencial ou em conjunto a exemplo do Ensino Híbrido, defendido por muitos autores como o futuro da educação.

\section{REFERÊNCIAS}

Atanásio, V.; Pereira, F. O. R.; Pereira, A. T. C. (2006). Laboratório experimental para ensino de iluminação em arquitetura através de um AVA. In: Encontro Nacional De Tecnologia Do Ambiente Construído, 2006, Florianópolis. Anais [...] .https://docplayer.com.br/62749668-Laboratorio-experimental-para-ensino-de-iluminacaoem-arquitetura-atraves-de-um-ava.html.

Beltrán, L. R. (1981). Adeus a Aristóteles: comunicação horizontal. Comunicação \& Sociedade, São Bernardo do Campo, IMS, ano III, nº 6, set. 1981.

EUREKA. Site da Eureka. (2020). Página inicial. https://eureka.pucpr.br/entrada/index.php?acao=carregando.

Ferreira, A. B. de H. (1986). Novo Dicionário da Língua Portuguesa. 2. ed. Rio de Janeiro: Nova Fronteira.

Fachin, O. (2010). Fundamentos de metodologia. 5aㅗ ed. São Paulo: Saraiva.

Florianópolis, n. esp., $2^{\circ}$ sem. 2010.

Gil, A. C. (2010). Como elaborar projetos de pesquisa. 5. ed. São Paulo: Atlas, 2010. 
Jaimes, E. I. G. (2021) Guía de enseñanza para el aprendizaje exitoso en educación a distancia universitária. RIDE. Rev. Iberoam. Investig. Desarrollo Educativo. vol.11 no.21 Guadalajara jul./dic.2020. Epub 09-Mar-2021

Learning Space (2020). Site do LearningSpace. https://www.learningspacedigital.com/. Acesso em: 24 nov. 2020.

Mattar, J.; Rodrigues, L. M. M.; Czeszak, W.; Graciani, J. (2020). Habilidades y funciones de tutores em línea em educación a distancia. EDUR - Educação em Revista. 2020;

36:e217439 DOI: http://dx.doi.org/10.1590/0102-4698217439

Moodle (2020). Site do Moodle, 2020. Página inicial. https://moodle.org/login/index.php.

Acesso em: 23 nov. 2020.

Rosenberg, Marc J. (2006). Beyond e-learning: approaches and technologies to enhance organizational knowledge, learning and performance. San Francisco: Pfeiffer, Salvador, ANPAD. [CD_ROM].

TELEDUC (2020). Site do Teleduc.

http://teleduc4.multimeios.ufc.br/pagina inicial/autenticacao cadastro.php.

Trigueiro, O. M. (2001). O estudo científico da comunicação: avanços teóricos e metodológicos ensejados pela escola latino-americana. PCLA, v. 2, n. 2, jan./mar. 2001.

\title{
COMPUTATIONAL TOOLS FOR CORRESPONDENCE COURSE AND THE EDUCATIONAL SITUATION IN THE PANDEMIC PERIOD OF COVID-19
}

\begin{abstract}
Distance learning is a teaching modality that, for a long time, has been an alternative for students, especially for those who are unable to attend graduation in the face-to-face format due to several factors such as: insufficient financial conditions; live in remote areas of the city; have children; work reasons, among others. With the arrival of the pandemic period of COVID-19 in the country, it became the main alternative not only to meet the emergencies, but also to continue the activities and contents of face-to-face teaching, making it necessary to adapt and reformulate the educational practices in this context. Therefore, in order to favor student learning, educational institutions use several computational resources that help access and stay in the courses offered, as well as a better use of the proposed contents. This study aims to analyze the computational resources used for distance learning, citing digital platforms and highlighting their advantages and disadvantages, in addition to assessing the effectiveness and excluding each resource from use. The survey method is used, based on the application of the technique of a structured questionnaire, aimed at students, in order to assess the quality of distance learning from their point of view. The results show that distance learning is highly sought after by students, especially in the pandemic context emerged, but this characteristic has several flaws, mainly with regard to computational resources and not meshes. Therefore, it is concluded that $\mathrm{EaD}$ has a huge capacity for growth, but has not yet met all the expectations expected, making the process of evolution of this modality difficult.
\end{abstract}

Keywords: Distance learning. Computational resources. Digital platforms. COVID-19. 